\title{
PHYSICAL SCIENCE OF MATERIALS
}

\section{Influence of Residual Pressure and Ion Implantation on the Structure, Elemental Composition, and Properties of (TiZrAlYNb)N Nitrides}

\author{
A. D. Pogrebnjak*a , I. V. Yakushchenko ${ }^{a}$, O. V. Sobol'b , V. M. Beresnev ${ }^{c}$, A. I. Kupchishin ${ }^{d}$, \\ O. V. Bondar ${ }^{a}$, M. A. Lisovenko ${ }^{a}$, H. Amekura ${ }^{e}$, K. Kono ${ }^{e}$, K. Oyoshi ${ }^{e}$, and Y. Takeda ${ }^{e}$ \\ ${ }^{a}$ Sumy State University, ul. Rimskogo-Korsakova 2, Sumy, 40007 Ukraine \\ ${ }^{b}$ National Technical University Kharkiv Polytechnical Institute, ul. Frunze 21, Kharkiv, 61002 Ukraine \\ ${ }^{c}$ Karazin Kharkiv National University, pl. Svobody 4, Kharkiv, 61022 Ukraine \\ ${ }^{d}$ Kazakh National Pedagogical University, pr. Dostyk 13, Almaty, 050010 Kazakhstan \\ ${ }^{e}$ National Institute for Material Science (NIMS), Tsukuba, 305-0003 Japan \\ *e-mail:alexp@i,ua \\ Received May 22, 2014; in final form, January, 13, 2015
}

\begin{abstract}
The nitrides of high-entropy alloys, (TiZrAlYNb)N, fabricated by cathodic vacuum arc evaporation are studied with electron microscopy, atomic force microscopy, laser scanning microscopy; energy-dispersive X-ray analysis, X-ray phase analysis, time-of-flight secondary-ion mass spectrometry; and hardness measurements. It is found that the deposition parameters influence the structure, surface morphology, element distribution, and mechanical properties. The structural-phase state of the coatings before and after the ion implantation of heavy negative gold ions $\mathrm{Au}^{-}$are compared.
\end{abstract}

DOI: $10.1134 / \mathrm{S} 1063784215080228$

\section{INTRODUCTION}

Multicomponent high-entropy alloys (HEAs) represent a new and promising class of functional materials. Because of a high mixing entropy of such systems (including no less than five metals with concentrations from 5 to $35 \%$ ), the formation of a disordered phase is stable and that of intermetallics during crystallization is prevented [1-3]. Thus, HEA-based coatings offer a stable structure and high performance characteristics.

Of greater interest for researchers, however, are HEA-based nitrides. They offer excellent physicomechanical properties (hardness and Young's modulus), tribological properties (wear resistance, low friction coefficient, etc.), and high thermal stability [4-11]. This is explained by the deformation hardening effect observed in solid solutions, crystal lattice distortions, and the formation of a nanocomposite structure (as well as in the case of nitride systems with a smaller amount of elements) [12-19].

One way of controlled variation of the structural, physicomechanical, and tribological properties of coating is ion implantation. In this case, impurity ions are embedded in a surface layer through bombarding the surface by high-energy ions [20-23]. It is therefore of particular interest to study the influence of ion bombardment on the structure and properties of nitride HEAs, since works concerning the influence of ion implantation on the HEA-based nanostructured nitride coatings are scarce.

\section{EXPERIMENTAL DETAILS}

We studied five-element nitrides of HEAs, (TiZrAlYNb)N, fabricated by cathodic vacuum arc evaporation. Cathodes for $\mathrm{Ti}-\mathrm{Zr}-\mathrm{Al}-\mathrm{Y}-\mathrm{Nb}$ HEAs were prepared by vacuum arc melting in high-purity argon. The prepared cathodes were multiply (5-7 times) recrystallized to provide a desired degree of homogenization.

Coatings were deposited with a Bulat-6 vacuum arc evaporator. To improve their strength characteristics and adhesion to a substrate made of $12 \mathrm{Kh} 18 \mathrm{~N} 9 \mathrm{~T}$ stainless steel, the substrate was negatively biased $\left(U_{b}=-150 \mathrm{~V}\right)$. The arc discharge current in the evaporator was in the interval $100-110 \mathrm{~A}$; the nitrogen pressure during deposition, $4 \times 10^{-4}-4 \times 10^{-3}$ Torr; and the thickness of the coatings, $8-9 \mu \mathrm{m}$.

The surface morphology of the coatings was examined by a scanning electron microscopy (SEM) equipped with a JEOL JSM-6010-LA (Japan) energydispersive spectrometer. Measurements were taken under low vacuum (about $7.5 \times 10^{-2}$ Torr) at an accelerating voltage of $20 \mathrm{kV}$. The images of the test sample surfaces and data for the elemental composition and the element distribution over the surface were obtained.

The surface roughness of the nitride HEAs was also studied under an SPI 3800N scanning electron microscope (Seiko Instrument, United States) that operated in the atomic force mode to image the surface topog- 


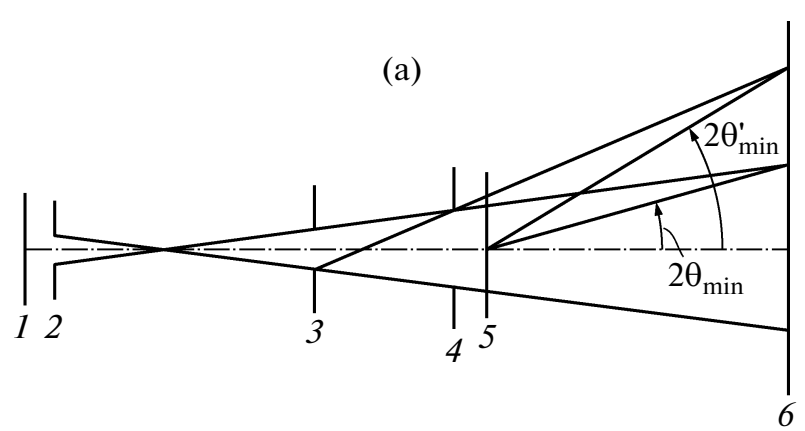

(b)

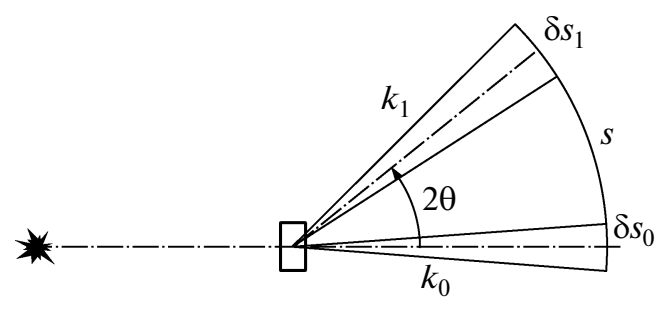

Fig. 1. General scheme for formation of primary and scattered radiations at small angles of incidence in the (a) direct and (b) reciprocal spaces: (1) source of radiation, (2-4) circular holes in collimator, (5) sample, and (6) detector plane.

raphy. $2 \mathrm{D}$ and $3 \mathrm{D}$ patterns were taken of $1 \times 1-, 2 \times 2-$, and $10 \times 10-\mu \mathrm{m}$ fragments of the coatings. The data were processed using the Gwyddion 2.33 software package.

The 2D and 3D images of the surface were also obtained by laser scanning microscopy, and the surface roughness over different scan areas was calculated. To this end, a Keyence VK-200 3D laser scanning microscope (Japan) was applied. The results were analyzed using the VK Analyzer program package.

Time-of-flight secondary ion mass spectrometry (ToF SIMS) was applied to study the element distribution in the coating. Measurements were taken with a Physical Electronics PHI TRIFT V nanoTOF instrument (Japan). This device has high spatial and mass resolutions owing to a triple-focus hemispherical electrostatic analyzer. As a result, the integral distribution of the elements in the coating over the depth (within the analysis time) and element distribution maps was plotted. Time-of-flight mass spectrometry exploits the fact that ions equal in energy but different in mass move with different velocities. Ions arising in a short event of ionization are accelerated by the electromagnetic field to the same energy and fly over a distance to a detector. From the time of flight, the mass of each ion is determined.

The phase and structure of the alloys were studied with a DRON-3M diffractometer ( $\mathrm{Cu} K_{\alpha}$ radiation). A graphite monochromator was used to monochromate the radiation. It was placed in the secondary beam (before the detector). The phase and structure (texture, substructure) were examined with conven-

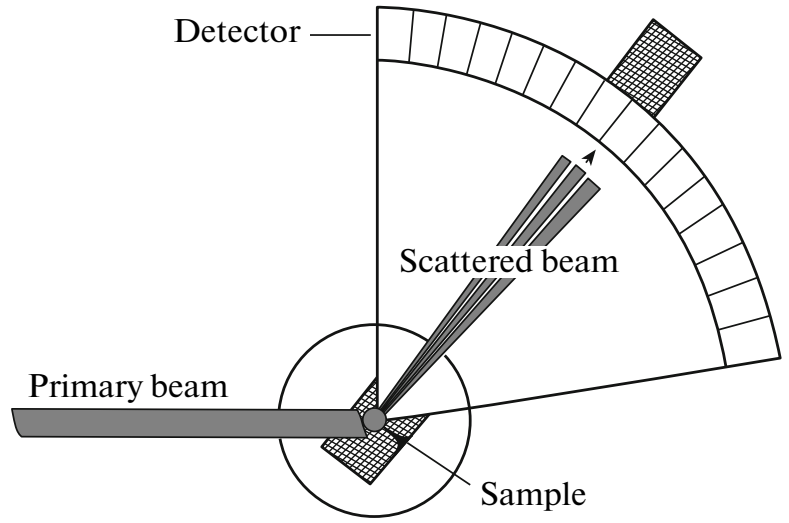

Fig. 2. Measuring diagram.

tional X-ray diffraction techniques, and conclusions were drawn from the positions, intensities, and shapes of diffraction peaks. The diffraction patterns were identified using the Powder Diffraction File dataset.

To carry out measurements at the grazing incidence of $\mathrm{Cu} K_{\alpha}$ radiation, the beam of primary radiation incident on the sample was collimated and thereby made narrow (Fig. 1). A set of small circular diaphragms spaced at large (compared with the size of the holes) distances approximated the plane wave conditions accurate to ratio $r / R$, where $r$ and $R$ are the radii of the holes in diaphragms 2 and 3, respectively (Fig. 1). Ratio $r / R$ determines the size of the primary beam projection onto the plane of the detector and also, with regard to a selected distance between sample 5 and detector 6 (Fig. 1), minimal angle $2 \theta_{\text {min }}$ (and, hence, $h_{\min }$ ) from which the scattered radiation intensity can be measured. The value of $h_{\mathrm{min}}$, in turn, determines the small-angle resolution of a given collimator and upper limit $D_{\max }$ of the size of inhomogeneities that can be resolved by a diffractometer, $D_{\max }=\pi / h_{\min }$.

Experiments were conducted on an RINT-2500 V $\mathrm{X}$-ray diffractometer equipped with a position-sensitive proportional counter (PSPC/MDGT) (Fig. 2). The working values of the voltage and current of the $\mathrm{X}$-ray diffractometer were equal to $40 \mathrm{kV}$ and $300 \mathrm{~mA}$, respectively. Measurements were made at angles of $3^{\circ}$, $10^{\circ}$, and $30^{\circ}$ for the as-deposited samples and $2^{\circ}$ for the ion-implanted ones.

The Vickers microhardness was measured with a DM8-B microhardness tester using a Berkovich trigonal pyramid under a load of $0.1 \mathrm{kN}$.

Ion implantation was accomplished using an ion accelerator described in [24]. Negative $60-\mathrm{keV} \mathrm{Au}^{-}$ions were produced using a cesium-assisted plasma-sputter ion source and a mass analyzer with sector magnets. A gold target was directly sputtered by a Xe arc in the presence of Cs atoms. The intensity of the ion beam was controlled by varying the arc current, target bias, and rate of Cs atom injection. A collimated ion beam fell into an irradiation chamber through an aperture 
Table 1. Deposition parameters and elemental composition of (TiZrAlYNb)N coatings

\begin{tabular}{|c|c|c|c|c|c|c|c|c|c|}
\hline \multirow{2}{*}{ Series no. } & \multirow{2}{*}{ Material } & \multirow{2}{*}{$U_{\text {bias }}, \mathrm{V}$} & \multirow{2}{*}{$P$, Torr } & \multicolumn{6}{|c|}{ Concentration/Measurement accuracy, at $\%$} \\
\hline & & & & $\mathrm{N}$ & $\mathrm{Ti}$ & $\mathrm{Zr}$ & $\mathrm{Al}$ & Y & $\mathrm{Nb}$ \\
\hline \multirow{2}{*}{1} & \multirow{6}{*}{$($ TiZrAlYNb)N } & \multirow{6}{*}{-150} & \multirow{2}{*}{$1.2 \times 10^{-3}$} & 46.00 & 15.55 & 11.47 & 10.28 & 10.74 & 5.96 \\
\hline & & & & \pm 0.12 & \pm 0.05 & \pm 0.16 & \pm 0.03 & \pm 0.17 & \pm 0.15 \\
\hline \multirow{2}{*}{2} & & & \multirow{2}{*}{$4 \times 10^{-4}$} & 35.25 & 18.92 & 12.86 & 15.20 & 10.94 & 6.83 \\
\hline & & & & \pm 0.07 & \pm 0.04 & \pm 0.12 & \pm 0.03 & \pm 0.12 & \pm 0.11 \\
\hline \multirow{2}{*}{3} & & & \multirow{2}{*}{$4 \times 10^{-3}$} & 57.76 & 12.45 & 8.75 & 6.81 & 8.81 & 5.42 \\
\hline & & & & \pm 0.13 & \pm 0.05 & \pm 0.16 & \pm 0.03 & \pm 0.16 & \pm 0.15 \\
\hline
\end{tabular}

Table 2. Lattice parameters, and entropy of formation, and enthalpy of formation of binary nitrides

\begin{tabular}{l|c|c|c|c|c}
\hline & TiN & ZrN & AlN & YN & NbN \\
\hline Lattice parameters, mm & 0.4242 & 0.4578 & 0.436 & 0.4877 & 0.4394 \\
Entropy of formation, J/mol deg & 30.31 & 38.93 & 20.93 & 46.05 & 43.96 \\
Enthalpy of formation, kJ/mol & 336.62 & 365.51 & 320.29 & 299.36 & 237.81 \\
\hline
\end{tabular}

mask $12 \mathrm{~mm}$ in diameter placed above the samples. The temperature of the samples was measured with thermocouples attached to the aperture mask. The implantation dose was $8 \times 10^{16}$ ions $/ \mathrm{cm}^{2}$ for the samples from the third series and $1 \times 10^{17}$ ions $/ \mathrm{cm}^{2}$ for the samples from the first and second series.

It should be noted that heavy gold ions were selected, first, because of the fact that when these ions are implanted into a nitride multicomponent coating, it is easy to construct an $\mathrm{Au}^{-}$ion profile using the Rutherford backscattering technique. Second, heavy gold ions produce extended disordered areas (near a thermal peak) and one incident ion with an energy of $60 \mathrm{keV}$ generates several tens of cascades (knockedout secondary ions). In this case, the sputtering effect is enhanced. From published experimental results, it follows that the concentration of implanted ions at high doses $\left(1.0 \times 10^{17}, 5.0 \times 10^{17}\right.$, and $7.5 \times 10^{17}$ ions $\left./ \mathrm{cm}^{2}\right)$ does not exceed $7-10$ at \% [20, 25]. Another advantage of gold ions is that they react to form additional phases with none of the elements constituting the alloy.

\section{RESULTS AND DISCUSSION}

Table 1 lists the parameters of the (TiZrAlYNb) N coatings and the results of energy-dispersive X-ray analysis (EDXA). The coatings were deposited at a constant negative bias applied to the substrate and at different nitrogen pressures in the working chamber. In this way, one can see how the concentration of the high-entropy alloy constituents depends on the deposition parameters.

It is seen that when the pressure grows from $4 \times 10^{-4}$ to $4 \times 10^{-3}$ Torr, the nitrogen concentration in the coatings increases considerably, whereas the concen- trations of the other elements, especially light elements ( $\mathrm{Ti}$ and $\mathrm{Al}$ ), decrease. Presumably, the decrease in their concentrations is associated with the element redistribution during deposition.

Table 2 summarizes the crystal lattice parameters for binary nitrides of the metallic constituents. It is seen that the respective values differ substantially. Such a difference causes strong lattice distortions and thereby influences the stress-strain state of the nitride HEAs, as was shown in $[4,8,26]$. In addition, Table 2 gives the values of the enthalpy and entropy of formation of the binary nitrides [27].

Below, we will discuss the results of SEM studies. SEM surface images for the samples from the second and third series are shown in Figs. $3 \mathrm{a}$ and $3 \mathrm{~b}$, respectively. It is seen that the surface of the coatings is in general continuous but contains a large amount of the droplet fraction (solidified droplets). This is known to be characteristic of coatings obtained by cathodic vacuum arc deposition [19]. Different separators and filters are applied to prevent the formation of the droplet function. Some of them were applied in our Bulat-6 setup. However, it seems to be unrealistic to totally avoid this effect.

Figure 4 shows the EDS maps of the element distribution over the coating surface. It is seen that the elements are distributed uniformly.

Of interest are areas with the largest drops. Their detailed SEM analysis (at a 12000× magnification) and the analysis of the element distribution over the surface of the droplets indicate that none of the elements prevails in the droplets. Specifically, the X-ray intensities of $\mathrm{Zr}$ and $\mathrm{Nb}$ atoms are higher than those of the other atoms, whereas the results of the same experiments with samples from the first and third series show that prevailing atoms are $\mathrm{Zr}$ and $\mathrm{Y}$ atoms. 
Atomic force microscopy (AFM) data, along with 3D laser microscopy (3D LM) data, made it possible to estimate the roughness of the coatings. Table 3 lists the rms roughness estimated on different areas of the coatings.

It is seen that the roughness slightly depends on the deposition parameters, namely, on the working gas pressure. The surface of the coatings obtained by vacuum arc deposition is rough because of the presence of the droplet fraction. As the working gas pressure rises, the ionization of plasma fluxes increases; the rate of travel of cathode spots over the cathode surface, as well as their number and size, grows; and the cathode temperature rises. This, in turn, increases the amount of the droplet fraction in the cathode plasma flux, as a result of which the roughness of coatings increases by about seven times (for pressures from $4 \times 10^{-4}$ to $4 \times$ $10^{-3}$ Torr).

An important condition for the stability of a coating, as well as for the improvement of its physicomechanical properties, is the uniformity of its composition and elemental distribution over the thickness. The thickness distribution of elements can be determined by ToF SIMS.

From the ToF SIMS element profiles in the (TiZrAlYNb) $\mathrm{N}$ coatings, it follows that the element distribution over the thickness is in general fairly uniform. Measurements were taken for $6 \mathrm{~h}$, and the etch depth was equal to $1.8-2.0 \mu \mathrm{m}$. The uniform distribution was observed in all samples.

Table 4 gives microhardness data (mean values averaged over a number of measurements) obtained by the Vickers method. The given nitride compounds demonstrate rather high microhardness: from 34 to $49 \mathrm{GPa}$. That the microhardness increases with working gas pressure is quite expectable. When the nitrogen pressure grows from 0.05 to 0.50 Torr, so does the crystallinity of the coatings and nanocrystallites arise (as follows from the stress-strain state of the coatings, see below). Thus, the fraction of grain boundaries also increases significantly. In nanocrystalline materials, grain boundaries serve as barriers for plastic deformation and thereby harden the material. In addition, X-ray diffraction analysis data indicate that the fraction of the fcc phase grows and fcc grains shrink. That is, the grain size approaches those values when the influence of dislocations on the coating's strength is negligibly small. However, there appear a great number of point defects, which, together with the lattice mismatch between the binary alloys constituting the coating, raises residual compressive stresses. Thus, the decrease in the grain size, the formation of the nanocrystalline phase, and a vast number of grain boundaries arising in the coating with increasing nitrogen pressure improve the strength and, accordingly, the mechanical hardness of the coatings $[8,11,12,15]$.

The X-ray diffraction analysis of the coatings was carried out with $\mathrm{Cu} K_{\alpha}$ and $\mathrm{Cr} K_{\alpha}$ radiations both in the standard and in the grazing-beam geometry (Figs. 1, 2). This

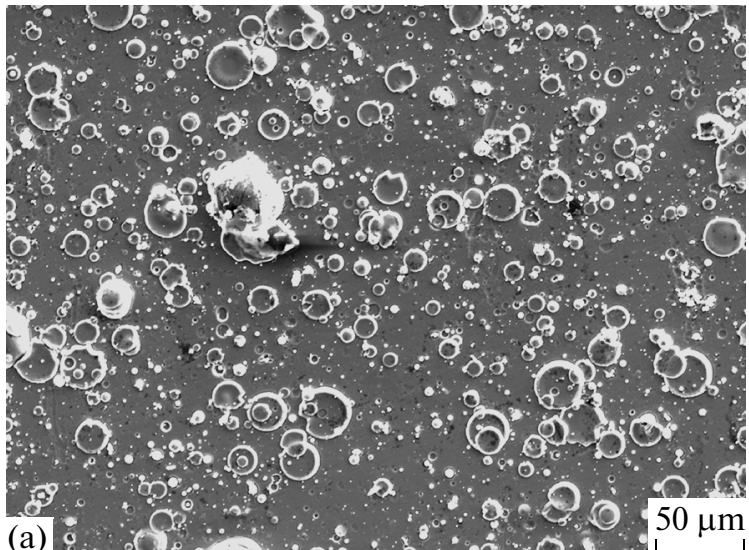

(a): $: 0$

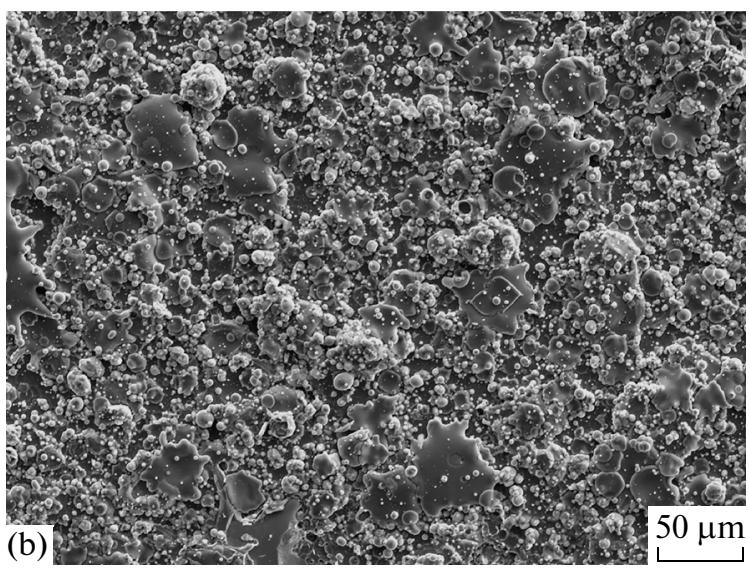

Fig. 3. SEM surface images of the (TiZrAlYNb) N coatings from the (a) second and (b) third series.

made it possible to compare the coating's state in the volume and on the surface modified by ion implantation.

The state of the coating in the volume was examined with $\mathrm{Cu} K_{\alpha}$ radiation. Information was derived from a 3.5-4.0- $\mu \mathrm{m}$-thick surface layer (such a thickness is typical of the given coatings). The respective diffraction spectra are shown in Fig. 5. It is seen that in the coatings deposited at the lowest pressure, the crystalline phase has a bcc lattice. This is typical of the structure of a multicomponent alloy where the nitride lattice is absent. It seems that the nitrogen present in the coating produces in this case some objects with an $\mathrm{X}$-ray amorphous structure, as indicated by a halo

Table 3. Rms surface roughness of the (TiZrAlYNb) N coatings

\begin{tabular}{c|c|c|c}
\hline \multirow{2}{*}{ Test area, $\mu \mathrm{m}$} & \multicolumn{3}{|c}{ Rms roughness } \\
\cline { 2 - 4 } & series no. 1 & series no. 2 & series no. 3 \\
\hline $10 \times 10$ & $0.671 \mu \mathrm{m}$ & $0.340 \mu \mathrm{m}$ & $2.321 \mu \mathrm{m}$ \\
$25 \times 25$ & $0.688 \mu \mathrm{m}$ & $0.254 \mu \mathrm{m}$ & $3.234 \mu \mathrm{m}$ \\
$50 \times 50$ & $0.842 \mu \mathrm{m}$ & $0.416 \mu \mathrm{m}$ & $2.993 \mu \mathrm{m}$ \\
\hline
\end{tabular}




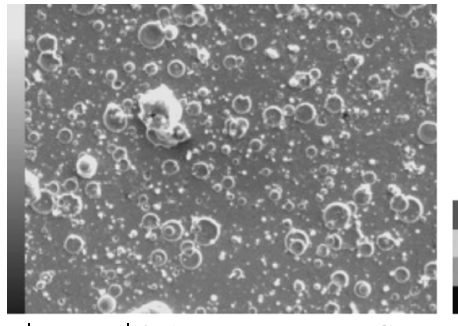

$0.1 \mathrm{~mm}$

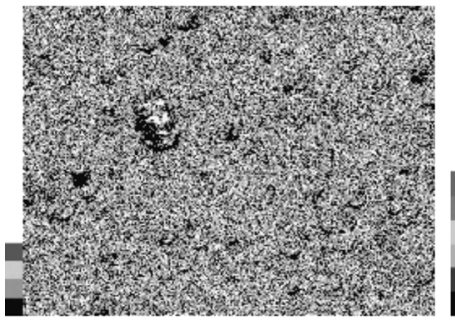

$-0.1 \mathrm{~mm}$

Al $K$

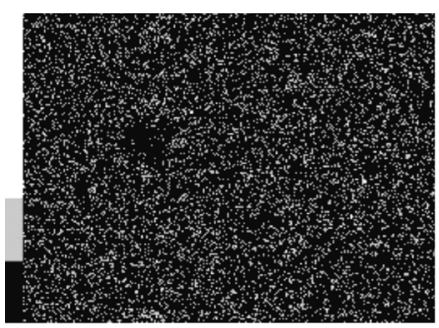

\lrcorner $0.1 \mathrm{~mm}$

$\mathrm{N} K$

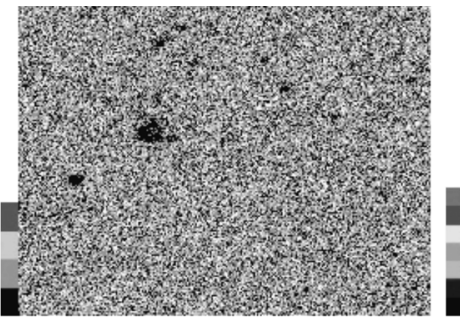

Ti $K$

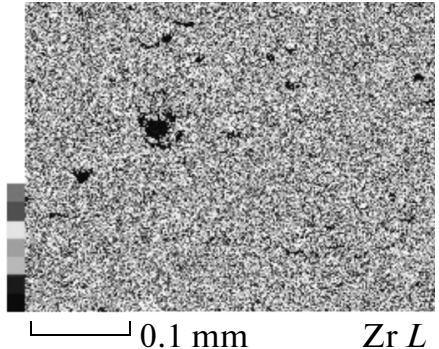

$\operatorname{Zr} L$

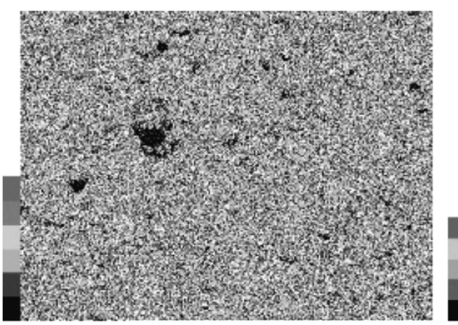

Y $L$

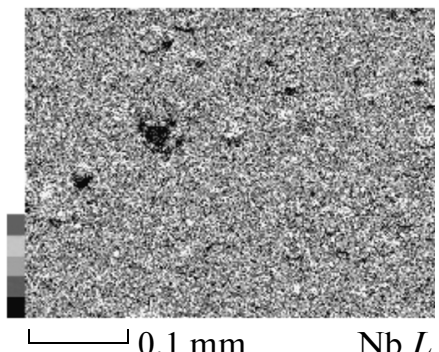

$\mathrm{Nb} L$

Fig. 4. Element distribution over the surface for the coatings from the first series.

appearing in angular range $2 \theta \approx 31^{\circ}-42^{\circ}$ with a maximum at $2 \theta \approx 36^{\circ}$.

The size of the bcc crystallites is also small and equals $7.7 \mathrm{~nm}$. The relative phase content in the coating can be estimated from the integral intensity ratio: the ratio of the bcc phase content to the content of the $\mathrm{X}$-ray amorphous phase is equal to $1: 2$.

For the coatings deposited at a higher pressure, $1.2 \times 10^{-3}$ Torr (Fig. 5, curve 2), the crystallinity is observed both in the bcc constituent phase and in the fcc nitride phase (structure of the $\mathrm{NaCl}$ type). The size of bcc grains is $11.5 \mathrm{~nm}$ on average; that of grains in the fcc nitride phase, about $5 \mathrm{~nm}$. The content ratio of the $\mathrm{fcc}$ and bcc phases determined from the ratio of areas under diffraction peaks is close to $1: 1$.

Spectra taken of the coatings of the third type, which were deposited at the highest pressure, show

Table 4. Hardness of the (TiZrAlYNb) N coatings

\begin{tabular}{l|c|c|c}
\hline & Series no. 1 & Series no. 2 & Series no. 3 \\
\hline Hardness, & $34.12 \pm 2.8$ & $40.12 \pm 3.4$ & $48.97 \pm 3.3$ \\
$H V_{0.1} \mathrm{GPa}$ & & & \\
\hline
\end{tabular}

that the crystallinity of the constituent phases is still higher (Fig. 5, curve 3). Here, the fcc phase prevails (the fcc-to-bcc phase intensity ratio is $3: 1$ ). The grain sizes in the bcc phase and fcc nitride phase were, respectively, about 10 and $7 \mathrm{~nm}$.

Data for multielement alloys obtained in [4-11, $14,21]$ indicate that the nitride phase has an fcc lattice. With a rise in the pressure, the dispersity of this phase decreases: its state varies from amorphous at the lowest pressure to nanoclustered with an ordered cluster size of $5 \mathrm{~nm}$ at a medium pressure and nanocrystalline at the highest pressure.

From the diffraction spectra taken at large and small (grazing) angles of incidence of $\mathrm{Cr} K_{\alpha}$ radiation with a wavelength of $0.2285 \mathrm{~nm}$ (the information depth in this case decreases from $2-3 \mu \mathrm{m}$ to about $100 \mathrm{~nm}$ at an angle of incidence of $3^{\circ}$ ) it follows that for the lowest pressure deposition $\left(4 \times 10^{-4}\right.$ Torr, Fig. 6a), both the volume and surface layers consist mainly of the bcc phase. When surface layers are irradiated in the beam grazing mode, a halo-type curve is absent.

In the coatings deposited at a higher pressure, $1.2 \times 10^{-3}$ Torr, the fcc phase prevailing in the volume (Fig. 6b; curves 1, 2), is also almost absent near the 


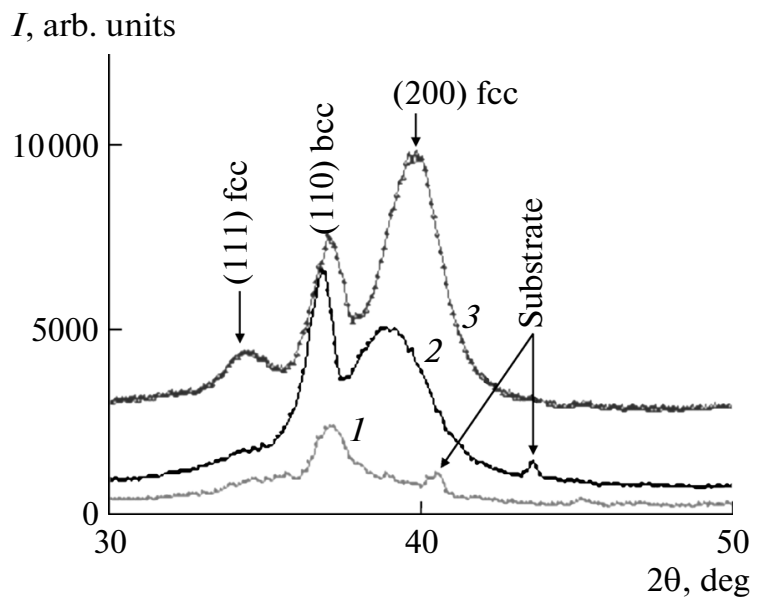

Fig. 5. Diffraction spectra taken of the (TiZrNbYAl)N coatings deposited at nitrogen pressure $P_{N}=$ (1) $4.0 \times 10^{-4}$, (2) $1.2 \times 10^{-3}$, and (3) $4.0 \times 10^{-3}$ Torr ( $\mathrm{Cu} K_{\alpha}$ radiation).

surface possibly because the constituents cannot reliably confine nitrogen.

Unlike the coatings obtained at low and medium pressures, those obtained at a high pressure contain largely the fcc phase. However, the trend toward an increase in the bcc phase in surface layers shows up in this case as well (Fig. 6c; curves 1,3).

Thus, comparing the phase compositions and structures of surface layers (the spectra are generalized in Fig. 7), one can see that when the pressure rises and the coating becomes saturated by nitrogen, the content of the fcc phase in surface layers grows. This confirms the supposition that this phase belongs to the base nitride with a NaCl-type structure (nitrogen makes the lattice stable, occupying octahedral interstices), which is usually the nitride of an elementary metallic constituent of the coating. It is also noteworthy that the preferred direction of fcc grain growth changes with pressure from the (111) direction at a low pressure to the (200) direction at a high pressure (Fig. 7; spectra 1,3).

To study the influence of ion implantation, diffraction spectra were taken of the irradiated coatings at the least grazing angle $\left(2^{\circ}\right)$, in which case, the information depth equals $100 \mathrm{~nm}$. Figure 8 shows fragments of the diffraction spectra for the nonirradiated samples (a grazing angle of $3^{\circ}$; spectra $1,3,5$ ) and for the implanted samples (spectra 2, 4, 6).

It is seen that upon irradiation to a dose of $10^{17}$ ions $/ \mathrm{cm}^{2}$, peaks from the fcc component in the surface layer grow and the scatter in the background becomes smaller, indicating smoothing-out of the irradiated surface. Thus, it may be supposed that the ballistic effect due to heavy ion irradiation causes selective sputtering of light nitrogen atoms from the surface, and hence, its smoothening. The former effect increases the relative content of the bcc phase in surface layers of the coating, which is seen in Fig. 8;
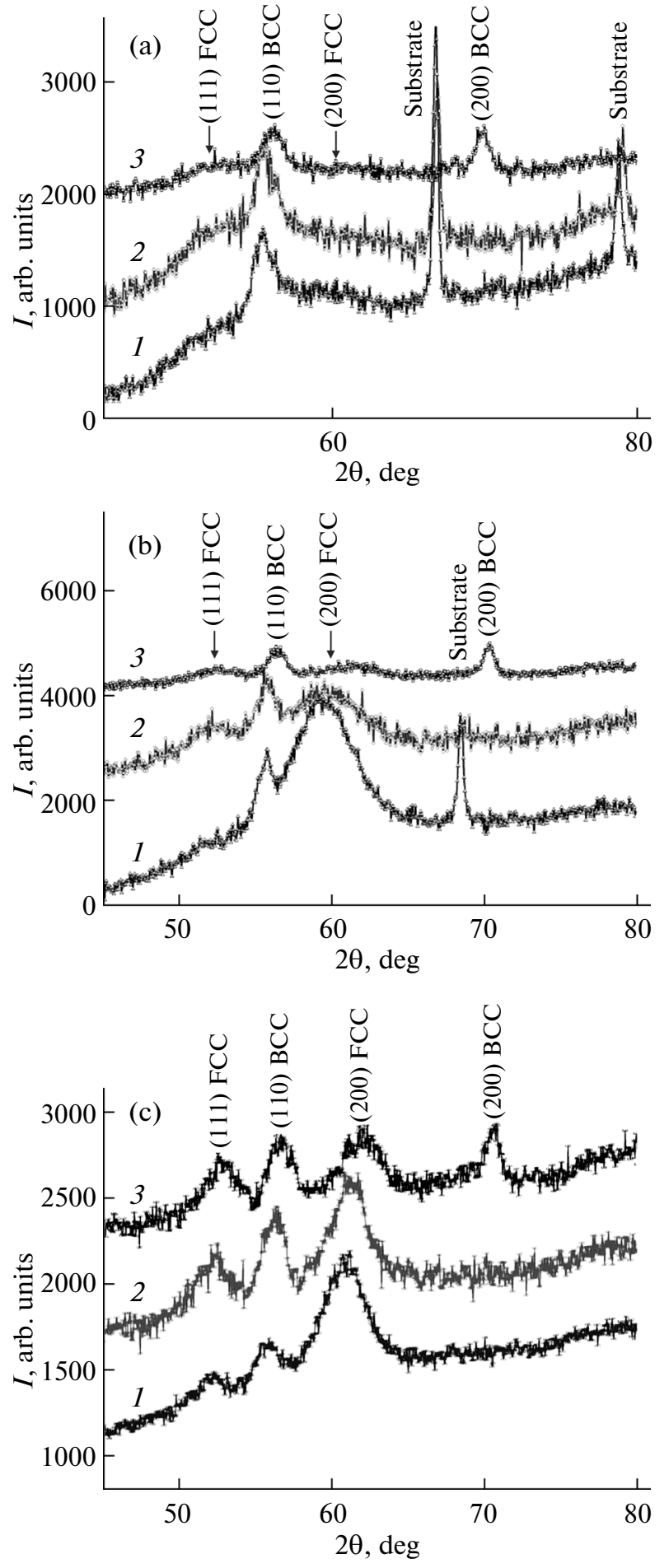

Fig. 6. Diffraction spectra taken of the (TiZrNbYAl) N coatings deposited at nitrogen pressure $P_{N}=$ (a) $4.0 \times 10^{-4}$, (b) $1.2 \times 10^{-3}$, and (c) $4.0 \times 10^{-3}$ Torr. The angle of incidence of the primary X-ray beam is (1) $30^{\circ}$, (2) $10^{\circ}$, and (3) $3^{\circ}$.

accordingly, the intensities of the peaks from the bcc phase, especially that of the (200) peak, grow. The latter effect suppresses the scatter of the background. 


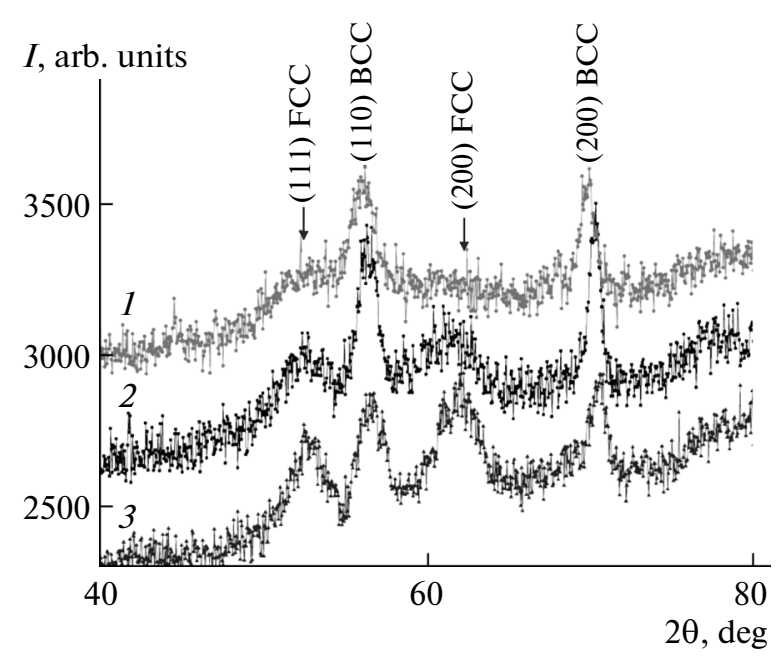

Fig. 7. Diffraction spectra of the (TiZrNbYAl)N coatings taken at a grazing angle of incidence $\left(3^{\circ}\right)$ of $\mathrm{Cr} K_{\alpha}$ radiation at nitrogen pressure $P_{N}=(1) 4.0 \times 10^{-4}$, (2) $1.2 \times 10^{-3}$, and (3) $4.0 \times 10^{-3}$ Torr.

\section{CONCLUSIONS}

We reported experimental data on the surface morphology, structure, and elemental and phase compositions of a (TiZrNbYAl) N high-entropy nitride system. It is shown that the working gas pressure in a deposition chamber influences the elemental composition, surface roughness, structure, and mechanical strength of the coatings. A rise in the $\mathrm{N}_{2}$ pressure during deposition with the substrate under a constant negative bias improves the crystallinity of the constituent phases, causes a bcc-fcc transition, and changes the growing texture from [110] to [200]. The structure of the coatings evolves from amorphous to nanoclustered and then nanocrystalline. The hardness of the coatings rises from 34 to $49 \mathrm{GPa}$.

In addition, irradiation by fast gold ions increases the content of the bcc phase in the surface layers of the coatings and also decreases the scatter of the background owing to partial sputtering of the surface.

\section{ACKNOWLEDGMENTS}

This work was made in the framework of the state programs "Formation of Superhard Nanostructured Multicomponent Coatings with High Physicomechanical Properties" (no. 0112U001382) and "Physical Grounds of Plasma Technology for Complex Processing of Multicomponent Materials and Coatings" (no. 0113U000137).

\section{REFERENCES}

1. J.-W. Yeh, Y.-L. Chen, S.-J. Lin, and S.-K. Chen, Mater. Sci. Forum. 560, 1 (2007).

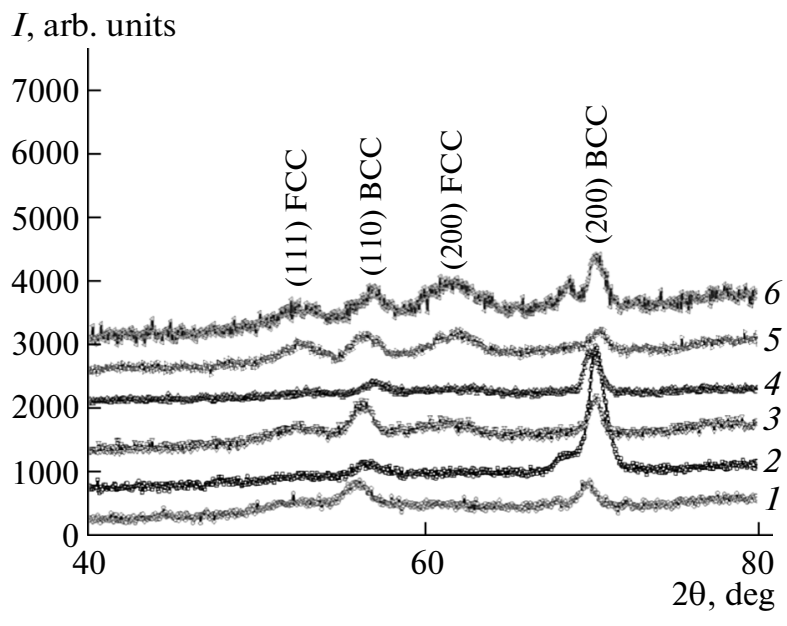

Fig. 8. Diffraction spectra taken of the (TiZrNbYAl) N coatings taken at a grazing angle of incidence $\left(2^{\circ}\right.$ and $\left.3^{\circ}\right)$ of $\mathrm{Cr} K_{\alpha}$ radiation at nitrogen pressure $P_{N}=(1,2) 4.0 \times$ $10^{-4},(3,4) 1.2 \times 10^{-3}$, and $(5,6) 4.0 \times 10^{-3}$ Torr. In the case of surface layers (to $100 \mathrm{~nm}$ thick), the spectra were taken at an angle of $2^{\circ}$ from the coatings subjected to implantation by $60-\mathrm{keV}$ gold ions to a dose of $(2,4) 1 \times$ $10^{17}$ and (6) $8 \times 10^{16}$ ions $/ \mathrm{cm}^{2}$.

2. Y. Zhang, T. T. Zuo, Z. Tang, M. C. Gao, K. A. Dahmen, P. K. Liaw, and Z. P. Lu, Prog. Mater. Sci. 61, 1 (2014).

3. S. A. Firstov, V. F. Gorban', N. A. Krapivka, and E. P. Pechkovskii, Kompoz. Nanostrukt., No. 2, 5 (2011).

4. R. Krause-Rehberg, A. D. Pogrebnyak, V. N. Borisyuk, M. V. Kaverin, A. G. Ponomarev, M. A. Bilokur, K. Oyoshi, Y. Takeda, V. M. Beresnev, and O. V. Sobol', Phys. Met. Metallogr. 114, 672 (2013).

5. D.-C. Tsai, Z.-C. Chang, L.-Y. Kuo, T.-J. Lin, T.-N. Lin, M.-H. Shiao, and F.-S. Shieu, Thin Solid Films 544, 580 (2013).

6. V. Braic, A. Vladescu, M. Balacean, C. R. Luculescu, and M. Braic, Surf. Coat. Technol. 211, 117 (2012).

7. S.-Y. Chang, Y.-C. Huang, C.-E. Li, H.-F. Hsu, J.-W. Yeh, and S.-J. Lin, JOM 65, 1790 (2013).

8. A. D. Pogrebnjak, I. V. Yakushchenko, G. Abadias, F. Chartier, O. V. Bondar, V. M. Beresnev, Y. Takeda, O. V. Sobol', K. Oyoshi, A. A. Andreyev, and B. A. Mukushev, J. Superhard Mater. 35, 356 (2013).

9. A. D. Pogrebnjak, V. M. Beresnev, A. V. Bondar', M. V. Kaverin, and A. G. Ponomarev, Russ. Phys. J. 56, 532 (2013).

10. A. D. Pogrebnyak, V. M. Beresnev, D. A. Kolesnikov, M. V. Kaverin, A. P. Shypylenko, K. Oyoshi, Y. Takeda, R. Krause-Rehberg, and A. G. Ponomarev, Tech. Phys. Lett. 39, 189 (2013).

11. A. D. Pogrebnjak, J. Nanomater. ID: 780125 (2013).

12. J. Musil, Surf. Coat. Technol. 207, 50 (2012).

13. S. Veprek, J. Vac. Sci. Technol. A 31, 050822 (2013).

14. P. H. Mayrhofer, C. Mitterer, L. Hultman, and H. Clemens, Prog. Mater. Sci. 51, 1032 (2006). 
15. A. D. Pogrebnyak, A. P. Shpak, N. A. Azarenkov, and V. M. Beresnev, Phys. Usp. 52, 29 (2009).

16. A. D. Pogrebnjak, A. P. Shpak, V. M. Beresnev, D. A. Kolesnikov, Y. A. Kunitskii, O. V. Sobol, V. V. Uglov, F. F. Komarov, A. P. Shypylenko, N. A. Makhmudov, A. A. Demyanenko, V. S. Baidak, and V. V. Grudnitskii, J. Nanosci. Nanotechnol. 12, 9213 (2012).

17. D. P. Borisov, D. Yu. Moshkov, S. V. Ovchinnikov, K. V. Oskomov, Yu. P. Pinzhin, V. M. Savostikov, and A. N. Tyumentsev, Izv. Vyssh. Uchebn. Zaved., Fiz. 50 (10), 13 (2007).

18. A. D. Pogrebnjak, O. V. Sobol, V. M. Beresnev, P. V. Turbin, G. V. Kirik, N. A. Makhmudov, M. V. Il'yashenko, A. P. Shypylenko, M. V. Kaverin, M. Yu. Tashmetov, and A. V. Pshyk, Nanostruct. Mater. Nanotechnol. IV: Ceram. Eng. Sci. Proc. 31 (7), 127 (2010).

19. A. D. Pogrebnjak and V. M. Beresnev, Nanocoatings, Nanosystems, Nanotechnologies (Bentham Sci., Oak Park, 2012).

20. V. I. Boiko, A. N. Valyaev, and A. D. Pogrebnyak, Phys. Usp. 42, 1139 (1999).
21. Yu. N. Tyurin and A. D. Pogrebnjak, Surf. Coat. Technol. 142-144, 293 (2001).

22. A. D. Pogrebnjak, S. N. Bratushka, V. M. Beresnev, and N. Levintant-Zayontsc, Russ. Chem. Rev. 82, 1135 (2013).

23. A. Pogrebnjak, S. Bratushka, and N. Levintant-Zayonts, J. Nanoelectron. Phys. 5, 01016 (2013).

24. N. Kishimoto, N. Umeda, Y. Takeda, C. G. Lee, and V. T. Gritsyna, Nucl. Instrum. Methods Phys. Res. B 148, 1017 (1999).

25. N. Okubo, Y. Takeda, H. Amekura, J. P. Zhao, V. T. Gritsyna, and N. Kishimoto, Nucl. Instrum. Methods Phys. Res. B 175-177, 663 (2001).

26. O. V. Sobol', A. A. Andreev, V. F. Gorban', N. A. Krapivka, V. A. Stolbovoi, I. V. Serdyuk, and V. E. Fil'chikov, Tech. Phys. Lett. 38, 616 (2013).

27. G. V. Samsonov, Nitrides (Naukova Dumka, Kiev, 1969).

Translated by $V$. Isaakyan 